\title{
Cured malakoplakia of the renal allograft followed by long-term good function: A case report
}

\author{
Eva Honsova ${ }^{a}$, Alena Lodererovaa ${ }^{a}$ Janka Slatinska ${ }^{b}$, Petr Boucek
}

\begin{abstract}
Background. Malakoplakia is an unusual chronic inflammatory disease with distinctive histopathological features rarely involving the parenchyma of a transplanted kidney, and to date less than ten cases have been reported.

Methods and results. We present a case of malakoplakia of a kidney graft in a 31 year old woman after simultaneous kidney and pancreas transplantation, which was successfully treated with quinolones. After the treatment of malakoplakia, she was monitored regularly, and her renal and pancreas grafts functioned well for the following 9 years, which is 12 years post transplantation. Moreover, 1 year after treatment of malakoplakia she became pregnant and gave birth to a healthy child.

Conclusion. Evaluation of a kidney biopsy sample represents the key to diagnosis of malakoplakia which is important for correct patient management. Treatment with antibiotics with intracellular penetration (quinolone type) may result in curing the disease. According to our knowledge, this is the first case of allograft renal malakoplakia after combined kidney and pancreas transplantation.
\end{abstract}

Key words: malakoplakia, renal allograft, combined kidney and pancreas transplantation

Received: August 11, 2011; Accepted: February 2, 2012; Available online: April 19, 2012

http://dx.doi.org/10.5507/bp.2012.020

${ }^{a}$ Department of Clinical and Transplant Pathology, Institute for Clinical and Experimental Medicine, Prague, Czech Republic

${ }^{b}$ Department of Nephrology, Institute for Clinical and Experimental Medicine, Prague

'Diabetes Centre, Institute for Clinical and Experimental Medicine, Prague

Corresponding author: Eva Honsova, e-mail:eva.honsova@ikem.cz

\section{INTRODUCTION}

Malakoplakia is a rare inflammatory disorder frequently associated with Escherichia coli infection in immunocompromised patients in whom defective bacterial killing by macrophages leads to the manifestation of the disease. The term malakoplakia is derived from the Greek words "malakos" which means soft, and "plakos", meaning plaques.

Malakoplakia was originally described in the urinary bladder, but can involve many other organs. However, renal parenchymal involvement is rare and to date less than ten cases have been reported in renal allografts ${ }^{1-3}$. The diagnosis can be confirmed only histologically and depends on microscopic detection of so-called MichaelisGutmann bodies. Before 1990, malakoplakia was a serious disease with a high mortality rate. Quinolones, antibiotics with high intracellular penetration are used in treatment and can cure malakoplakia.

\section{CASE REPORT}

A 31 year old woman had been suffering from diabetes mellitus (DM) type I since the age of 16. Because of severe organ complications of DM, she underwent cadaveric kidney-pancreas transplantation 12 years ago (in February 1999). She was immunosuppressed with
Tacrolimus and Mycophenolate Mofetil. The patient had a histologically verified episode of acute rejection of the pancreas on the 15th day after transplantation (grade II, using Drachenberg's criteria) and was treated with steroids with good response. During the following 3 years she was treated for repeated urinary tract infections. She was admitted to the hospital for the same complaints in 2001. Her serum creatinine level was $147 \mu \mathrm{mol} / \mathrm{L}$ (one month before admission, her creatinine level was $104 \mu \mathrm{mol} / \mathrm{L})$. There was no proteinuria, and an examination of spun urine sediment showed the presence of 5-10 leukocytes and no red cells or cellular casts. There was evidence of repeated bacteriuria, and Escherichia coli and Staphylococcus aureus had grown from cultures of the urine 3 times during the last 2 years, and were also growing at this time. Her hypertension was under control (with blood pressure 120/80 $\mathrm{mm} \mathrm{Hg}$ ). The level of blood glucose was $5.7 \mathrm{mmol} / \mathrm{L}$ (normal range 3.6-5.59), and the glycated hemoglobin value was $7.1 \%$ (normal range less than $6 \%$ ). The values for total protein, albumin, electrolytes, and lipids were normal. There was no recent history of anorexia, nausea, vomiting, fever, lymphadenopathy or systemic disease. Hematologic and liver laboratory tests were normal. Tests for viral hepatitis $\mathrm{B}$, and $\mathrm{C}$ were negative. Testing for CMV and EBV were also negative. Ultrasonographic examination of the kidney and pancreas grafts showed normal pancreas and normal kidney graft with "forgotten" double pig-tail stent in the pelvis. The 


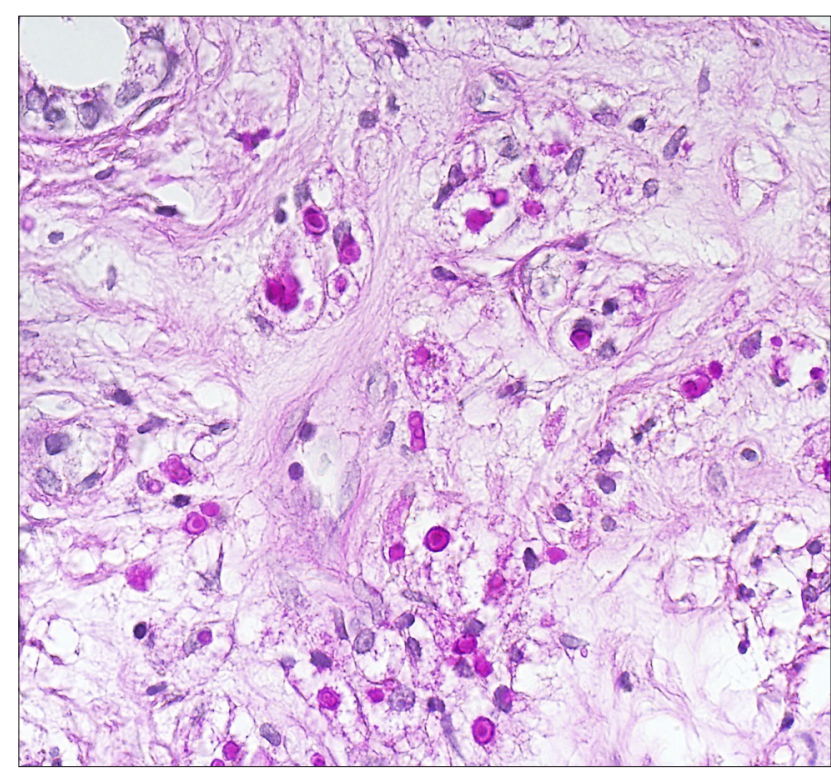

Fig. 1. Malakoplakia of the kidney graft with completely destroyed parenchyma and PAS positive purple MichaelisGutmann bodies with targetoid appearance (PAS, high power field).

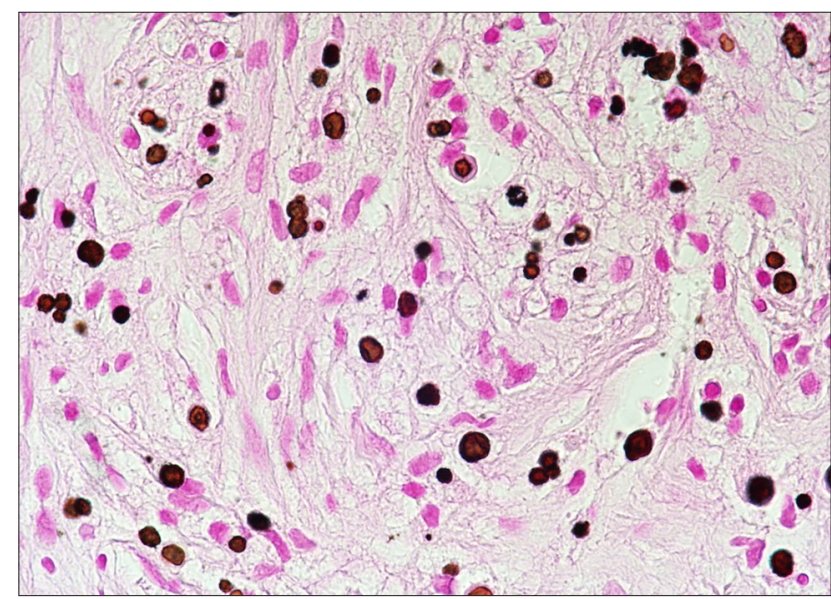

Fig. 2. Malakoplakia of the kidney graft; von Kossa stain with diagnostic positive Michaelis-Gutmann bodies (von Kossa stain, high power field).

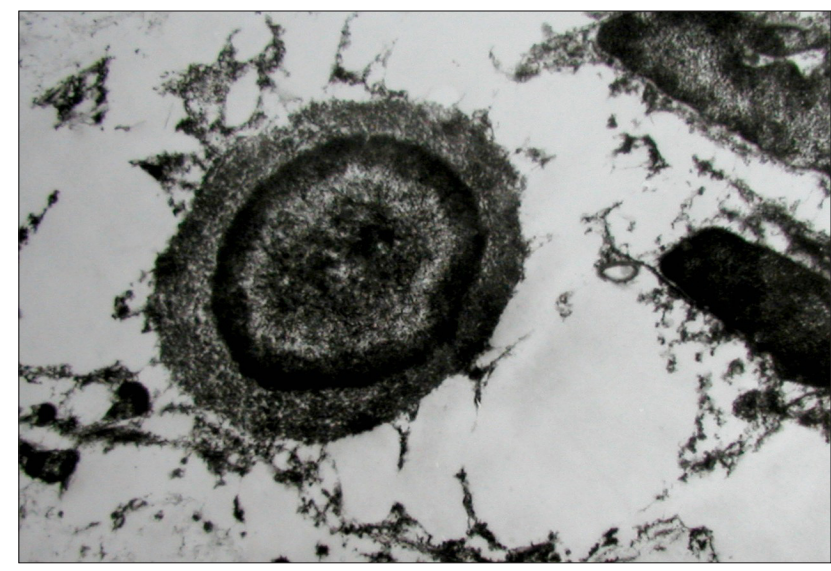

Fig. 3. Electron microscopy with a concentric layered figure corresponding to classic Michaelis-Gutmann bodies. clinical diagnostic suspicion was rejection, and biopsies of both grafts were performed. There were no pathologological findings in the pancreas graft.

The kidney biopsy sample was divided for immunofluorescence (IF) and light microscopy (LM). The sample for IF contained 2 glomeruli, both were negative for immunoglobulins. Peritubular capillaries were $\mathrm{C} 4 \mathrm{~d}$ negative. In light microscopy, the kidney biopsy was $23 \mathrm{~mm}$ long, and the normal kidney cortex appeared only in a small part of the sample. The remainder revealed completely destroyed renal parenchyma. This area showed predominantly mesenchymal tissue with chronic inflammatory cells, histiocytes and numerous PAS and von Kossa's positive Michaelis - Gutmann (MG) bodies with typical targetoid appearance (Fig. 1, 2). MG bodies were confirmed ultrastructurally (Fig. 3). Focally there was active inflammation with formation of microabscesses. Muscle arteries showed muscular hypertrophy, and arterioles showed mild hyalinosis.

The diagnostic conclusion was: Malakoplakia in the renal allograft, and active infection with micro-abscess formation.

\section{Follow-up}

The patient was treated with antibiotics with intracellular penetration (quinolone type), and simultaneously immunosuppression was reduced. Her renal functions improved during the following month (with a serum creatinine level of $105 \mu \mathrm{mol} / \mathrm{L})$.

Six months later, she suffered from short-term nausea and vomiting, and was admitted to the hospital. Her S-Cr had increased to $145 \mu \mathrm{mol} / \mathrm{L}$, and a second renal biopsy was performed.

The sample obtained for IF contained cortex of kidney tissue with $5 \mathrm{gli}$, and staining for immunoglobulins, and for C4d in PTCs were negative. In light microscopy, there were 8 gli which were unremarkable. There was no inflammation, and focal interstitial fibrosis was recognized. The diagnostic conclusion was: nonspecific focal interstitial scarring, no morphological features of rejection, no malakoplakia.

Her renal function improved spontaneously with only supportive therapy within several days after rehydration. She has been monitored regularly and her renal and pancreas functions are stable. Both grafts have remained in situ. Her S-Cr level was $110 \mu \mathrm{mol} / \mathrm{L}$ after the treatment of malakoplakia and remained at the same level for the following 9 years, which is 12 years post transplantation. Moreover, 1 year after treatment of malakoplakia she became pregnant and gave birth to a healthy child.

\section{DISCUSSION}

Malakoplakia represents an uncommon form of chronic inflammatory disease with distinctive histopathological features. Diagnosis can be determined only histologically. The targetoid structures, so-called Michaelis-Gutmann bodies which represent the key diagnostic marker, were 
in fact discovered in human medicine by Prof. von Hansemann, in 1901 (ref. ${ }^{4}$ ). Prof. von Hansemann read about a similar disease in a veterinary journal. Then he discussed this with his assistant Dr. Gutmann and provided him with details of this case. Dr. Michaelis was an expert biochemist, and Michaelis and Gutmann agreed to study this new disease in co-operation. Finally they published their results in 1902, one year before von Hansemann's paper. Both papers were published in German, and the error probably occurred because the texts were never translated completely ${ }^{4}$. Now, Hansemann's histiocytes and Michaelis-Gutmann bodies are known.

The precise pathogenesis of malakoplakia is still unknown. A favorite theory assumes an abnormal macrophage response because of defective lysosomal function ${ }^{5}$. It has been suggested that macrophages in malakoplakia are capable of phagocytosis but unable to digest the bacteria. There is general agreement that a patient with malakoplakia has an underlying disease involving an abnormal or altered immune response, and that microorganisms also play a role in the pathogenesis, especially E. coli which is found in more than $80 \%$ of cases $^{6}$. Before 1990, malakoplakia was a serious disease with a high mortality rate and poor recovery of renal function. At that time, early nephrectomy represented the recommended treatment of choice with subsequent withdrawal of immunosuppressive therapy ${ }^{7}$. In the 90 s, quinolones, antibiotics with high intracellular penetration, were first reported to cure malakoplakia ${ }^{8}$.

Malakoplakia can affect many organs and soft tissues but most frequently involves the urinary tract. However, renal parenchymal involvement is rare and accounts for only $15 \%$ of the urinary tract cases. Malakoplakia in renal allograft patients only rarely affects the renal allograft itself, and to date less than ten cases have been reported. According to our knowledge, this is the first case of allograft renal malakoplakia after combined kidney and pancreas transplantation.

\section{ACKNOWLEDGEMENTS}

This study was supported by the Institute for Clinical and Experimental Medicine institutional grant MZO 00023001.

Authors are very grateful to Mrs. Lois Russel for the assistance with correction of English text.

\section{REFERENCES}

1. Pusl T, Weiss M, Hartmann B, Wendler T, Parhofer K, Michaely H. Malacoplakia in a renal transplant recipient. Eur J Intern Med 2006;17(2):133-5.

2. Hušek K, Sobotová D. Diagnosis of malacoplakia in a transplanted kidney by needle biopsy. Cesk Patol 2000;36(2):65-70.

3. Puerto IM, Mojarrieta JC, Martinez IB, Navarro S. Renal malakoplakia as a pseudotumoral lesion in a renal transplant patient: a case report. Int J Urol 2007;14(7):655-7.

4. Dasgupta P, Womack C, Turner A, Blackford H. Malacoplakia: von Hansemann's disease. BJU International 1999;84:464-9.

5. van Crevel R, Curfs J, van der Ven AJ, Assmann K, Meis JF, van der Meer JW. Functional and morphological monocytes abnormalities in a patient with malakoplakia. Am J Med 1998; 105:74-7.

6. Streem S. Genitourinary malakoplakia in renal transplant recipients: Pathogenic, prognostic and therapeutic considerations. J Urol 1984;132:10-2.

7. Voort P, Velden J, Wassenaar R, Silberbusch J. Malacoplakia. Two case reports and a comparison of treatment modalities based on a literature review. Arch Intern Med. 1996; 156(5):577-83.

8. van Furth R, van Wout JW, Wertheimer PA, Zwartendijk J. Ciprofloxacin for treatment of malakoplakia. Lancet 1992;339:148-9. 